\title{
Psychiatric out-patients' views on talking about sex
}

\author{
M. J. Crawford and T. Shaw
}

\begin{abstract}
Desplte widespread acceptance that the sexual history is an important part of psychiatric assessment, concern continues to be raised that such questions are often neglected. It has been suggested that one reason for this is the bellef of staff that patients do not want to discuss sexual matters. The response of 65 out-patients to a questionnaire concerning their attitudes and expectations to being asked questions about sex is reported. The majortty of patients expected there to be some inquiry about sexual matters. While detalled enquiry was not anticipated, patients stated that most questions would not make them feel uncomfortable. This study does not support the view that patients are reluctant to give a sexual history.
\end{abstract}

The importance of asking psychiatric patients about sexual matters is highlighted by the established links between sexual dysfunction. mental illness and its treatment (Mitchell \& Popkin, 1982; Kockott \& Pfieffer, 1996). The impact of HIV and increased awareness of psychosexual problems have led to renewed demands that doctors pay more attention to the sexual histories of patients (Lewis, 1990). However, research has consistently reported that while doctors believe it is important to take psychosexual histories these questions are frequently not asked (Nussbaum, 1989). A recent audit of the case notes of patients admitted to a general adult psychiatric service reported that only one of 100 sets of notes included a detailed sexual history (Singh \& Beck, 1997). It has been suggested that the most likely reason for the failure to ask questions about sexual matters is the belief of medical staff that patients "do not want to discuss sexual matters" (Mitchell et al, 1996).

The purpose of this study was to examine the attitudes and expectations of psychiatric outpatients to being asked questions on sexual matters.

\section{The study}

The sample included all new adult (aged 18 to 65) patients referred for non-urgent psychiatric assessment to the out-patient department of the Royal Free Hospital, in Hampstead, north
London. We asked patients to complete a threepage questionnaire including socio-demographic details (age, gender, marital and employment status, education, religion, nationality and ethnicity) and questions about attitudes and expectations to being asked questions regarding sexual matters. These consisted of 13 items derived from locally recommended guidelines (Departments of Psychiatry and Child Psychiatry. Maudsley Hospital, London, 1987) and detailed in Table 1. Patients were first asked "At some point during the assessment by the psychiatrist, do you expect to be asked about ...". They were then asked "how would you feel if, at some point, the psychiatrist asked you about . . . ". Patients had a range of options from 'very uncomfortable' to 'very comfortable' to which they could respond. Finally, they were asked if when discussing sexual matters they would prefer to speak to a male or female doctor. or to one who was younger. We piloted the questionnaire on an earlier group of patients and found it to be acceptable and understandable.

\section{Findings}

We estimate that $40 \%$ of clinic attenders were unable to be included in the study because there was insufficient time between their attendance at the clinic and the time they were due to see the doctor. We gave 67 people questionnaires, 60 agreed to complete them. but three did not complete all sections. Half the patients were male $(n=34,51 \%)$, the mean age was 35 years, $43 \%$ were single, $26(43 \%)$ were unemployed, the majority were of British nationality $(43,72 \%)$, White $(50,83 \%)$ and Christian (35, 59\%).

Forty-nine $(86 \%)$ expected that at least one of the topics listed would be asked by the psychiatrist. The median response was that six of the items listed in the table would be raised (interquartile range 2-11). Twenty-two patients (39\%) stated that they would be comfortable answering questions on all of the listed topics. In an attempt to identify the characteristics of patients who were most likely to feel uncomfortable when asked sexual questions logistic regression analysis was used to examine the 
Table 1. Expectations and attitudes of patients to each of the 13 questionnaire items.

\begin{tabular}{|c|c|c|}
\hline & $\begin{array}{l}\text { Number of } \\
\text { patients } \\
\text { expecting } \\
\text { to be asked } \\
\text { questions on the } \\
\text { topic listed } \\
n=58(\%)\end{array}$ & $\begin{array}{l}\text { Number of } \\
\text { patients feeling } \\
\text { uncomfortable/ } \\
\text { very } \\
\text { uncomfortable if } \\
\text { this topic was } \\
\text { raised, } n=57(\%)\end{array}$ \\
\hline $\begin{array}{l}\text { Your sex life } \\
\text { Faithfulness }\end{array}$ & $\begin{array}{l}47(73)^{1} \\
37(64)\end{array}$ & $\begin{array}{c}16(27)^{2} \\
7(12)\end{array}$ \\
\hline $\begin{array}{l}\text { about sex } \\
\text { Sexual abuse }\end{array}$ & $\begin{array}{l}33(57) \\
32(55)\end{array}$ & $\begin{array}{l}18(31)^{1} \\
11(19)\end{array}$ \\
\hline $\begin{array}{l}\text { Physical difficulties } \\
\text { having sex }\end{array}$ & $30(52)$ & \\
\hline $\begin{array}{l}\text { Sexual assault } \\
\text { Your first sexual }\end{array}$ & $28(50)$ & 10 (18) \\
\hline $\begin{array}{l}\text { experience } \\
\text { Contraception } \\
\text { Puberty } \\
\text { Sexual fantasies }\end{array}$ & $\begin{array}{l}27(47) \\
25(43) \\
25(42) \\
21(36)\end{array}$ & $\begin{array}{c}18(31) \\
4(7) \\
6(8)^{3} \\
26(43)^{3}\end{array}$ \\
\hline $\begin{array}{l}\text { Unusual sexual } \\
\text { practices } \\
\text { Masturbation } \\
\text { Homosexuality }\end{array}$ & $\begin{array}{l}17(28) \\
16(27) \\
15(26)\end{array}$ & $\begin{array}{l}16(28) \\
29(49)^{\prime} \\
14(25)\end{array}$ \\
\hline
\end{tabular}

Change in denominator resulting from not all sections of questionnaire being completed by all respondents: 1. $n=59$.

2. $n=60$.

3. $n=58$.

characteristics of the 35 of $57(61 \%)$ patients who had responded that they were uncomfortable answering one or more of the items listed. This group of patients were more likely to be below 30 years of age (odds ratio $(\mathrm{OR})=9.9,95 \% \mathrm{CI}=1.5-$ 65), single (OR 19, 95\% CI 1.1-122) and have received fewer years of full-time education (OR $5.5,95 \% 1.2-25)$ compared to the 22 of 57 (39\%) who responded that they would be comfortable answering all the questions. There was no association between being uncomfortable and nationality, gender, job status or religious faith. The majority of patients stated that they had no preference regarding the gender and age of the doctor that asked them sexual questions (40 of $57(72 \%)$ regarding gender and 356 of $57(61 \%)$ regarding age). However, the 35 patients who reported feeling uncomfortable answering questions were more likely to state that they would prefer to speak to someone of the same gender (14 of $35(40 \%)$ compared to 3 of $22(16 \%)$ patients who responded that they would feel comfortable answering questions, chi-squared test for difference in proportions with one d.f.=4.5, $P=0.03$ ).

\section{Comment}

This study has demonstrated that the majority of patients attending this out-patient clinic expected the doctor to ask them something about their sex life and would feel comfortable being asked most of the items listed. It is possible that the answers given may not reflect how patients would actually feel if these questions were asked and social desirability may have affected the responses of patients. The study did not include patients who were referred for urgent assessment and these findings may not be applicable to this patient group. The response rate was good, with $90 \%$ of subjects agreeing to take part.

It is clear that patients did not expect to be asked questions on many of the listed items, but even these topics were not associated with high levels of discomfort. These results challenge the view that older people feel more uncomfortable than young people when asked sexual questions and suggest that higher levels of education rather than social class may be associated with lower levels of discomfort. Another factor that may have influenced the level of discomfort felt by patients is whether or not the subject being discussed related to their own experiences. This could have resulted in our finding that greater numbers of patients thought they would feel uncomfortable discussing issues such as masturbation and their sex life, rather than issues such as sexual assault and sexual fidelity. This and other possible explanations need further investigation combining quantitative and qualitative methodologies.

While the majority of patients stated that the gender and age of the person asking them sexual questions did not matter, it is important to note that almost half those that responded they would find answering questions about sexual matters difficult, said they would prefer to speak to a doctor of the same gender. This finding supports the suggestion of Singh \& Beck (1997) that patients should, where possible, be offered a choice about when and with whom they would like to discuss this aspect of their history. While we should always be sensitive when questioning any patient about sexual issues the findings of this study do not support the concerns of clinicians that patients are reluctant to discuss sexual matters as part of a general psychiatric assessment.

\section{Acknowledgements}

We are grateful to Mrs Margaret Hobbs, OutPatient Nurse, for her help with data collection and to Professor Michael King for his comments on an earlier draft of this paper. Part of this research was undertaken while M.C. was em- 
ployed as a Grovelands Priory/Royal Free Hospital research registrar.

\section{References}

DEPARTMENTS OF PSYCHIATRY AND CHILD PSYCHIATRY, MAUDSLEY HOSPITAL, LONDON (1987) Psychiatric Examination. Notes on the Eliciting and Recording Clinical Information in Psychiatric Patients (2nd edn). London: Oxford University Press.

Kоскотт, G. \& PFiefrer, W. (1996) Sexual disorders in nonacute psychlatric outpatients. Comprehensive Psychiatry, 38, 56-61.

LEWIS, C. E. (1990) Sexual practices-are physicians addressing the issues? Journal of Internal Medicine, $\mathbf{5}$, 578-581.

Mrtchell, D.. Gatson Grindel. C. \& Laurenzano. C. (1996) Sexual abuse assessment on admission by nursing stafi in general hospital psychlatric settings. Psychiatric Services, 47, 159-164.
MrTChell. J. E. \& POPKIN, M. K. (1982) Antipsychotic drug therapy and sexual dysfunction in men. American Joumal of Psychiatry. 139, 633-637.

Nussbaum, M. (1989) Attitudes versus performance in providing gynaecological care to adolescents by paediatricians. Joumal of Adolescent Health Care, 10. 203-208.

SinGH, S. P. \& BECK. A. J. (1997) No sex please we're British - taking a sexual history from in-patients. Psychiatric Bulletin, 21, 99-101.

*Michael J. Crawford, Research Fellow, Institute of Psychiatry, London SE5 8AZ, and Therese Shaw, Senior Registrar, Royal Free Hospital, London NW3

*Correspondence 